\title{
SOBRE LOS AUTORES
}

Roberto Carlos Hernández López. Licenciado en Relaciones Internacionales (UNAM), maestro en Estudios Latinoamericanos (UNAM), doctorado en Filosofía y Psicoanálisis (Universidad Complutense de Madrid). Profesor definitivo de Relaciones Internacionales (UNAM-FES, ACATLÁN).

Mario Magallón Anaya. Licenciado y maestro en Filosofía (UNAM), doctor en Estudios Latinoamericanos (UNAM). Investigador titular definitivo del CCyDEL-UNAM. Profesor de Licenciatura y Posgrado en la Facultad de Filosofía y Letras. Miembro del SNI Nivel II. Miembro del Padrón de Posgrado de Estudios Latinoamericanos de la UNAM. Líneas de investigación: Filosofía de la educación en América Latina, filosofía política en América Latina y filosofía latinoamericana. Autor y coordinador de libros y artículos.

Estela Fernández Nadal. Profesora y doctora en Filosofía por la Universidad Nacional de Cuyo (1982 y 1996). Actualmente es docente titular de la Universidad Nacional de Cuyo e investigadora independiente del CONICET. Línea de investigación: Pensamiento latinoamericano de los siglos XIX y XX. Es autora de unos 60 trabajos publicados en revistas de su especialidad y en libros colectivos, así como de dos libros: Itinerarios socialistas en América Latina (Córdoba, Alción Editora, 2001, 223 pp.) y Revolución y utopía. Francisco de Miranda y la independencia hispanoamericana (Mendoza, EDIUNC-Universidad Nacional de Cuyo, 2001, 360 pp.).

Rolando Sierra Fonseca. Licenciado en Historia por la UNAH, magíster en Ciencias Sociales con mención en desarrollo y ética social por el ILADES/Universidad Gregoriana de Roma y magíster en Ciencias Socia- 
les con mención en estudios de la cultura por la Universidad Academia de Humanismo Cristiano de Santiago de Chile. Ha sido coordinador del Informe sobre Desarrollo Humano de Honduras del PNUD y es profesor del magíster en trabajo social y demografía social de la UNAH. Ha publicado libros y artículos en el campo de la historia, el desarrollo y las ciencias sociales. Sus últimas publicaciones son las siguientes: $\mathrm{Co}$ lonia, independencia y reforma. Introducción a la historiografia hondureña; El problema de la idea de nación en Honduras en el siglo XIX; Ramón Oquelí. Una lucha tenaz contra el olvido.

Juan Huaylupo Alcázar. Licenciado en Sociología (Universidad Nacional Mayor de San Marcos. Lima, Perú), magíster scientiae en Ciencias Sociales (FLACSO, sede México), candidato a doctor en Economía (UNAM), candidato a doctor en Comunicación y Paz (Universidad para la Paz. Ciudad Colón, Costa Rica). Actualmente se desempeña como catedrático, docente e investigador en la Escuela de Administración Pública y Sistema de Estudios de Posgrado de la Universidad de Costa Rica. Líneas de investigación: Estado y administración pública, comercio exterior, globalización, política social y económica, y epistemología en ciencias sociales.

Eva Leticia Orduña Trujillo. Licenciada en Derecho por la Facultad de Derecho (UNAM), maestra en Estudios Latinoamericanos por la Facultad de Filosofía y Letras (UNAM), doctora en Estudios Latinoamericanos por la Facultad de Filosofía y Letras (UNAM). Investigadora Asociada "C" de tiempo completo del Centro Coordinador y Difusor de Estudios Latinoamericanos (UNAM). Líneas de investigación: Derechos humanos, derecho internacional, relaciones internacionales. Autora de artículos, folletos y memorias relacionados con sus temas.

Isabel de la Rosa Quiñones. Licenciada en Sociología (UAM-Azcapotzalco), pasante de Maestría en el Programa de Posgrado en Estudios Latinoamericanos (UNAM). Líneas de investigación: Teoría de los mo- 
vimientos sociales; actores y movimientos sociales en América Latina; actores sociales y cultura política. Autora del artículo "De la simulación a la tolerancia relativa", publicado en agosto de 2000 en la $R e$ vista de Ciencias Religiosas de la Universidad del Valle de Atemajac, Jalisco.

Silvia Soriano Hernández. Doctora en Estudios Latinoamericanos (UNAM), profesora del Posgrado en Estudios Latinoamericanos (UNAM). Ha sido docente en diferentes universidades del país. Investigadora del CCYDEL, ha participado en eventos académicos nacionales e internacionales en temas de su especialidad. Líneas de investigación: movimientos sociales, movimientos indígenas, identidad y género. Ha publicado diversos artículos y es autora del libro Lucha y resistencia indígena en el México colonial (México, UNAM-CIHMECH, 1994) y coordinadora del libro A propósito de la insurgencia en Chiapas (México, ADICH, 1994).

Kande Mutsaku Kamilamba. Doctor en Estudios Latinoamericanos (UNAM), director del Posgrado en Estudios Humanísticos en el Instituto Tecnológico y de Estudios Superiores de Monterrey, Campus Ciudad de México. Miembro del SNI. Autor de Desarrollo y liberación, utopías posibles para África y América Latina, 2003; compilador de Globalización vista desde la periferia, 2002.

María del Rosío Vargas Suárez. Maestra en economía y política internacional (CIDE), doctora en Ingeniería (UNAM), investigadora definitiva adscrita al área de estudios de la globalidad del Centro de Investigaciones sobre América del Norte, de la cual es coordinadora. Profesora-tutora de la maestría en estudios México-Estados Unidos del Posgrado de la Facultad de Ciencias Políticas de la UNAM. Línea de investigación: El sector energético estadounidense: implicaciones para México. Autora y coordinadora de libros y artículos, su publicación más reciente es "Las políticas exteriores de Estados Unidos, Canadá y México en el umbral del siglo XXI, del que fue corresponsable. 